\title{
Creating an Adaptive Ecosystem Management Network Among Stakeholders of the Lower Roanoke River, North Carolina, USA
}

\author{
$\underline{\text { Susan L. Manring }}^{1}$ and Sam Pearsall ${ }^{2}$
}

\begin{abstract}
Adaptive ecosystem management (AEM) requires building and managing an interorganizational network of stakeholders to conserve ecosystem integrity while sustaining ecosystem services. This paper demonstrates the usefulness of applying the concepts of interorganizational networks and learning organizations to AEM. A case study of the lower Roanoke River in North Carolina illustrates how an AEM network can evolve to guide stakeholders in creating a shared framework for generative learning, consensus building through collaboration, and decision making. Environmental professionals can use this framework to guide institutional arrangements and to coordinate the systematic development of cohesive interorganizational AEM networks.
\end{abstract}

Key Words: adaptive ecosystem management; stakeholder networks; virtual organizations; learning organizations; negotiations; multivariate decision making; institutional power; leadership

An Army officer, a business executive, four ecologists, and six lawyers walk into a bar.

The bartender looks up, frowns, and says,

"What is this-a joke?"

\section{INTRODUCTION}

Effective ecosystem management requires that the ecosystem stakeholders, defined as those with vested interests and individuals with management authority as well as those with expert knowledge, make balanced, multivariable decisions about how best to conserve ecosystem integrity while sustaining ecosystem services (Christensen et al. 1996, Berkes and Folke 1998, Richter et al. 2003). To achieve these objectives, adaptive ecosystem management (AEM) uses a stepwise, experimental approach to management with feedback loops that monitor and ensure that the strategy better defines and approaches the objective (Holling 1978, 1982, 1995, Walters and Holling 1990, Gunderson et al. 1995, Holling and Meffe 1996, Walters 1997, Lee 1999, Westley 2002, Anderson et al. 2003, Prato 2003). Hence, an essential goal of AEM is to improve resource management by changing institutional arrangements and improving coordination among the public, private, and nonprofit organizations that comprise the interorganizational network (Gunderson et al. 1995, Christensen et al. 1996, Lee 1999, Rogers et al. 2000, Anderson et al. 2003).

When multiple stakeholders are involved, as is nearly always the case with complex ecosystem management, the interorganizational network grows into a "superordinate" entity that is both larger and, as the result of emergent properties, greater than the aggregated stakeholder individuals and organizations that comprise it (Westley 1995, Schneider et al. 2003). Successful efforts to build, manage, and maintain such an interorganizational network, i.e., to develop an effective institutional ecosystem, depend largely on the extent to which this network evolves as a learning organization whose members become capable of developing and pursuing systemic solutions through collaborative consensus-building dialogues (Gunderson et al. 1995, Westley 1995, Manring et al. 2003).

Many ecosystem management initiatives in the United States and elsewhere use forms of networked, collaborative decision making (Pearsall 1984, Dewitt 1994, Feyerherm 1995, Selin and 
Chavez 1995, Westley 1995, 2002, Howes and Dewitt 1998, Imperial 1999, Wondolleck and Yaffee 2000, Berkes et al. 2003). However, there has been no explicit analysis of interorganizational networks for AEM as emerging learning organizations (Manring et al. 2003). To address this gap, an interdisciplinary framework that integrates network and learning organization models was developed as a methodological tool to be used for the improvement of ecosystem management. It was first tested through post hoc application to a county land-use management project (Manring et al. 2003). The present analysis, based on current negotiations on the lower Roanoke River in North Carolina, USA, is a further explanation of this interdisciplinary framework.

\section{METHODS}

Although organizational theory first examined dimensions of organizational learning in the seminal work of Argyris and Schon (1978), the concept of the learning organization has only been widely recognized since the late 1990s (Easterby-Smith et al. 1998, 1999, 2000, Easterby-Smith and Lyles 2003). The technical view of organizational learning focuses primarily on the effective processing of, interpretation of, and response to information (see, for example, Argyris and Schon 1978 and 1996, Lave and Wenger 1991), whereas the social perspective views organizational learning as a social construction, as a political process, and as a cultural artifact (Easterby-Smith and Araujo 1999). To some extent we have incorporated both views in this paper, although most of the development of the learning organization derives from the social perspective.

The literature of learning organizations has an action orientation that can help to identify, promote, and evaluate the quality of organizational learning processes (Easterby-Smith et al. 1998, EasterbySmith and Araujo 1999). Since 1990, much of the work on the learning organization has been articulated by Peter Senge (1990a,b, Senge et al. 1999). Senge's emphasis on systems thinking and dialogue, in particular, has been useful in our application of the learning organization model to adaptive ecosystem management (AEM). This article will illustrate some of the characteristics of an AEM network, e.g., a unifying purpose; independent yet interdependent members; voluntary and informal links; multiple leaders; multilevel, redundant, and nonhierarchical integration; and trustworthiness. The collaborative learning processes used in such a system, i.e., the pursuit of systemic solutions, the development of a transcendent vision, the creation of a community of commitment, and holographic or systems thinking, are also discussed.

To explore the dimensions of such a network, we focus on the one that developed naturally among the stakeholders of the lower Roanoke River in North Carolina, USA, hereinafter called the "Roanoke network." This network evolved without deliberate design and without reference to the principles of organizational theory. We offer a point-by-point commentary on the evolution of the Roanoke network and illustrate the ways in which it evolved as a learning organization, as well as some of the obstacles that it encountered. Our goals are to heighten awareness of the nature, dimensions, and vital signs of an evolving and viable interorganizational ecosystem network and to provide environmental professionals with a diagnostic, although not prescriptive, paradigm based on network and learning organization models that will stimulate collaborative, generative learning among the diverse stakeholders of adaptive ecosystems.

Following an introduction to the Roanoke ecosystem, we discuss the new Roanoke network, first as a virtual interorganizational network, and second as a learning organization. Next we look more specifically at the nature of interorganizational transactions in the Roanoke network. We then focus on the diffusion of Roanoke network practices back to its stakeholder organizations. Lastly, we consider dimensions of leadership and stewardship in the Roanoke network.

\section{The lower Roanoke River in North Carolina}

When the Roanoke River (Fig. 1) crosses the state boundary from Virginia into North Carolina, it is already a very large river, with roughly the same mean flow as the Colorado River through the Grand Canyon. Following destructive flooding caused by a hurricane in 1940, the U.S. Congress authorized one federal and two private dams near the VirginiaNorth Carolina boundary for the purposes of flood control and power generation (Fig. 2). Downstream of the dams, the Roanoke floodplain provides habitat for the largest and least fragmented system of bottomland forested ecosystems and one of the 
most diverse and numerous populations of migratory fishes on the east coast of the United States. Beginning in 1979, a coalition of public and private partners began to build systems of conservation lands and managed fisheries downstream of the dams.

Since 1994, a negotiating coalition has evolved in response to the impacts of dam operations on downstream conservation lands and waters in the floodplain. The formal contexts for these negotiations emerged from the requirement of the Federal Energy Regulatory Commission (FERC) that Dominion Power seek relicensing for its two dams. Later, this same coalition secured Congressional support for a Section 216 study to potentially change the operating policies of the $U$. S. Army Corps of Engineers (USACE) dam (USACE 2001). Table 1 contrasts the FERC and USACE processes. The negotiating coalition consists of private companies, e.g., Dominion Power and Weyerhaeuser Corporation; federal agencies including FERC and the USACE plus resource agencies like the U.S. Fish and Wildlife Service (USFWS); and several nonprofit organizations, including conservation groups like The Nature Conservancy (TNC) and representative groups like the Roanoke River basin and Lake Gaston associations. For a more comprehensive overview of the river, operating policies, system models, research components, and the flow of these negotiations, see Pearsall et al. (2005).

The negotiating coalitions that came together through these two processes have become an interorganizational network that has matured as a learning organization in terms of capabilities to understand and reduce the impacts of the regulated flows produced by the operations of the three dams, and to restore and maintain in-stream and riparian ecosystems. Many important lessons can be derived from this evolutionary process. In this article, the roles and relationships among the lower Roanoke River stakeholders are developed and explained through an overlay of two paradigms: the emergence of an interorganizational network and the maturation of that network as a learning organization dedicated to and expecting to be informed by AEM (Lee 1999, Rogers et al. 2000, Anderson et al. 2003). These paradigms are discussed and compared in the context of the two different, federally managed negotiating and planning processes on the Roanoke.

\section{The Roanoke River ecosystem as a virtual interorganizational network}

When members of stakeholder organizations find themselves in negotiations to support a wide variety of objectives for a large, complex ecosystem, they tend to form a network for AEM (Westley 1995, Anderson et al. 2003, Schneider et al. 2003). As they work to overcome the unstructured nature of collaborative relationships, they socially construct a new institutional form and a systems perspective on AEM (Westley 1995, Berkes and Folke 1998, Scheffer et al. 2002, Westley et al. 2002). Of the three types of networks, i.e., internal, stable, and dynamic, identified by Miles and Snow (1986), AEM is best suited to and most likely to result in a dynamic network, i.e., a shifting set of alliances among strategic stakeholders. Each stakeholder organization is independent and collaborates on a specific component issue or opportunity (van Alstyne 1997). While it exists, this network is a "highly decentralized and densely integrated social system that maximizes mutual influence and communication" (Bovasso 1992) in the spirit of collaboration. Such a network has no hierarchical power or authority; it is a socially facilitated political system rather than a tightly bonded, homogeneous, hierarchically controlled system. It depends on sets of negotiations that are derived from the lack of comprehensively predefined institutional roles and relationships.

Ecosystems are complex, exhibiting highly diverse and highly interactive compositions, structures, and functions. The stakeholders who comprise an interorganizational AEM network will reflect that complexity. As local and regional private and institutional interests, industries and small businesses, local governments, planning commissions or boards, county governments, and government agencies at the state, interstate, and federal levels come together to resolve multivariate ecosystem management objectives, they become an institutional analogue for the ecosystem(s) they seek to manage (Westley 1995, Pritchard and Sanderson 2002, Scheffer et al. 2002, Westley et al. 2002, Olsson et al. 2004). The resulting network or interorganizational hub is a "virtual web" entity (Franke 1999), rather than an actual organization. 
Fig. 1. Roanoke River basin.

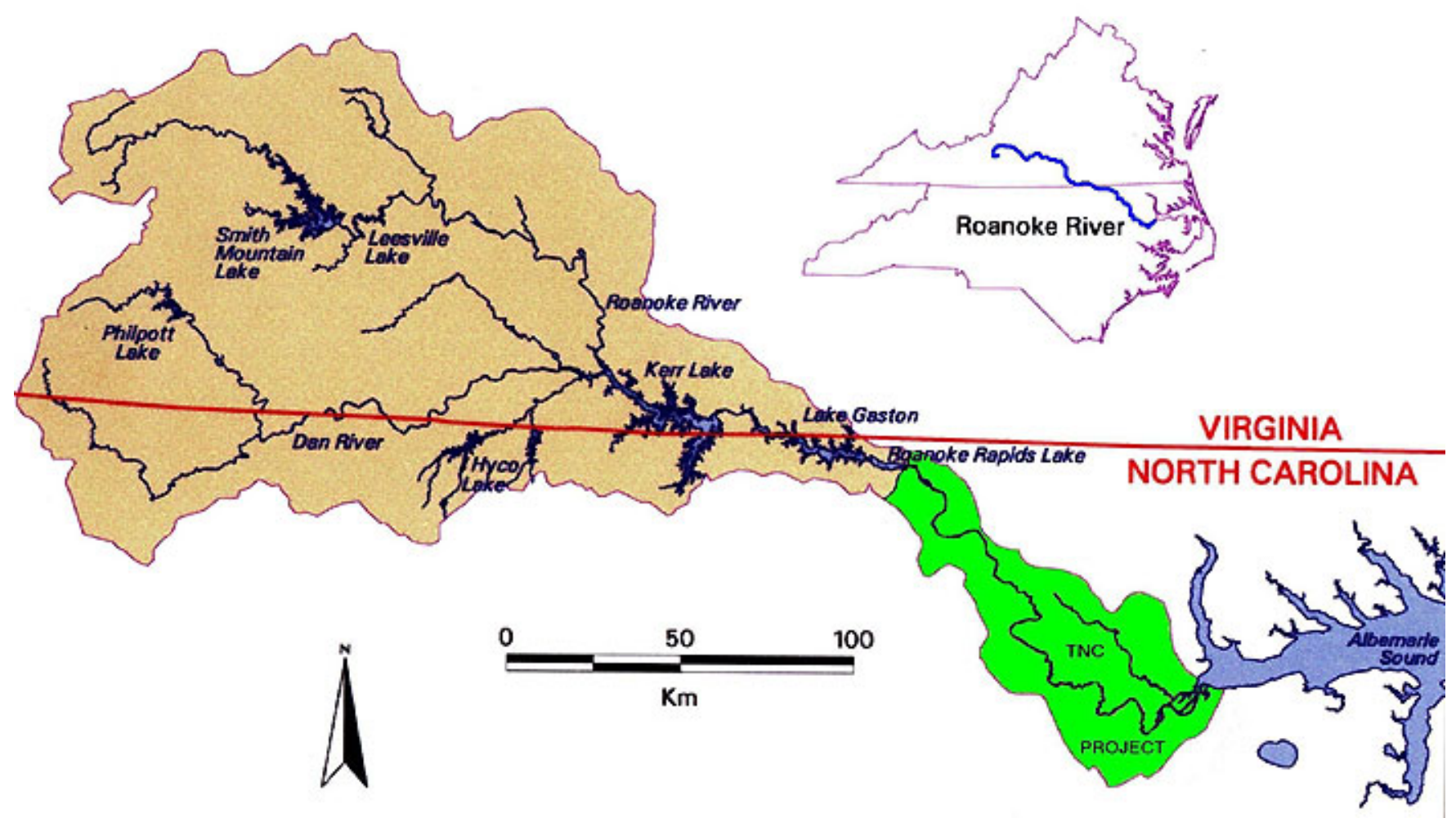

The complexity, diversity, and connectivity of the Roanoke ecosystem thus tend to be reflected in the complexity, diversity, and connectivity of the network of stakeholders previously referred to as the Roanoke network. Stakeholders represent particular components and linkages, but not all components and linkages are represented. In the Roanoke River negotiations, essentially the same stakeholders have played critical and consistent roles in both the Dominion Power-FERC relicensing negotiations and the USACE 216 negotiations. Stakeholders in both processes include Dominion Power; TNC; several divisions of the North Carolina Department of Environment and Natural Resources; the North Carolina Wildlife Resources Commission; the Virginia Departments of Conservation and Recreation, Environmental
Quality, and Game and Inland Fisheries; the USFWS; associations of lake-shore homeowners and sport paddlers such as canoeists and kayakers; and so on. About half of these stakeholders are mandated by laws or regulations to participate in one or both processes; the other half elected to participate. Although farmers, timber managers, anglers, and hunters are among the most important stakeholders in the Roanoke network, they tend to be independent and private in their activities, and, for the most part, did not self-identify as stakeholders and insist on a voice in these processes.

Many of the parties to the Dominion Power and USACE negotiations have some sort of regulatory power, but most do not. Regulatory authorities are characteristically fragmented and noncomplementary, 
Fig. 2. Schematic indicating three dams and downstream conservation lands.

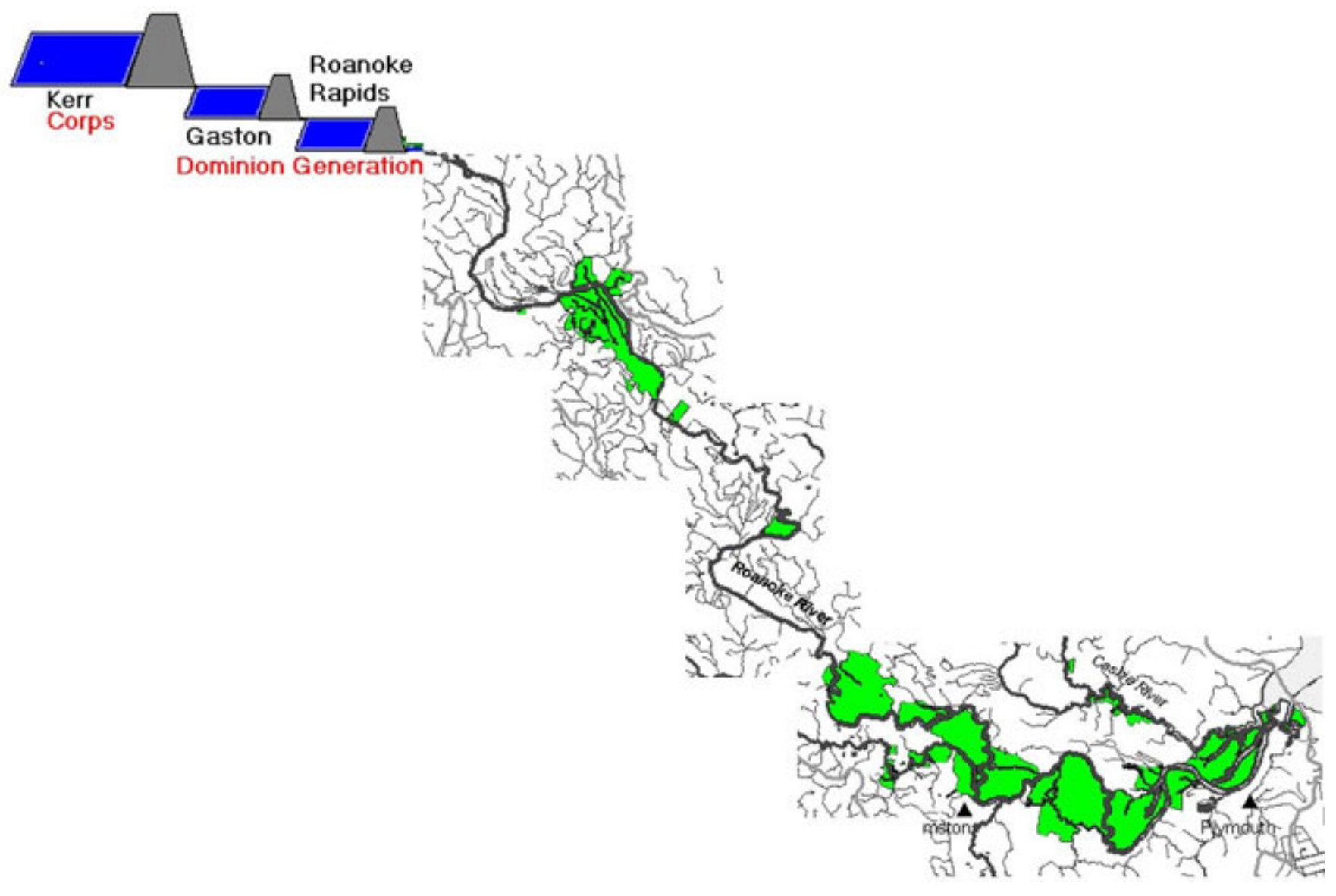

and together do not constitute the necessary and sufficient set of authorities to produce unified, comprehensive results.

Figure 3 illustrates the complexity of the virtual network that evolved in the Dominion Power negotiations. In Fig. 3, six kinds of participants are identified, and in Fig. 4, representative examples are provided. FERC and Dominion Power are directly bound by the fact that FERC has final authority over the issuance of a license to Dominion. However, the North Carolina Department of Environment and Natural Resources (NC DENR) may issue water quality conditions for the license that FERC must incorporate. Dominion assembled a large group of additional stakeholders to propose other conditions for the license. In Fig. 5, for example, TNC, a significant riparian landowner, attempted to encourage most of the other parties to influence the license. In Fig. 6, all of the parties with an interest in the issue of between-day scheduling of releases coalesced to develop recommendations for its resolution. Consultants and other outside experts were recruited. All of the parties in Fig. 6 were connected, i.e., the parties with an interest were completely networked around this particular issue. It should be noted that consultants and outside experts became network resources, without reference to which stakeholder brought them to the table, and also that FERC was not a party to the resolution of the issue, but, at this point, merely an overseer of the process. A similar series of diagrams could be drawn to illustrate the USACE process. A comprehensive diagram of the entire virtual network that emerged from the simultaneous USACE and Dominion processes would include so 
Table 1. Contrasting the Federal Energy Regulatory Commission (FERC) relicensing and U.S. Army Corps of Engineers (USACE) Section 216 processes.

\begin{tabular}{|c|c|c|}
\hline & FERC Relicensing & USACE Section 216 Study \\
\hline Authority & $\begin{array}{l}\text { Federal Power Act (FPA) of } 1920 \text { as } \\
\text { amended }\end{array}$ & $\begin{array}{l}\text { Section } 216 \text { of the River, Harbor, and } \\
\text { Flood Control Act of } 1970 \text { as amended }\end{array}$ \\
\hline Stimulus to launch & $\begin{array}{l}\text { Expiration of an existing license for a } \\
\text { specific FERC-authorized hydroelectric } \\
\text { project }\end{array}$ & $\begin{array}{l}\text { Congressional authorization and } \\
\text { appropriation for a specific USACE } \\
\text { project, e.g., dam, in question. This may } \\
\text { be at the request of the Department of } \\
\text { Defense, or it may be a direct result of a } \\
\text { Congressional initiative, e.g., in response } \\
\text { to a constituent request }\end{array}$ \\
\hline Additional legal compliance & $\begin{array}{l}\text { National Environmental Policy Act of } \\
1969 \text { (NEPA) as amended } \\
\text { Water Pollution Control Act of } 1972 \text { as } \\
\text { amended, in particular, Section } 401 \text { of } \\
\text { the Federal Clean Water Act }\end{array}$ & $\begin{array}{l}\text { National Environmental Policy Act of } \\
1969 \text { (NEPA) as amended }\end{array}$ \\
\hline
\end{tabular}

many stakeholders and so many issue-mediated connections among them that it would appear chaotic or, more likely, opaque.

During the negotiations leading to the emergence of the Roanoke network, the softening of institutional influence maps was very challenging, especially among those agencies with regulatory responsibilities, because such softening could have been misinterpreted as abdication of mission (e.g., Pritchard and Sanderson 2002). Nevertheless, as the Roanoke stakeholders continued to work together, without deliberately choosing to do so they incorporated a number of the principles elucidated for networked organizations (Powell 1990, Lipnack and Stamps 1997, Podolny and Page 1998, Gulati and Gargiulo 1999), knowledge networks (Lee 1999, Skyrme 1999, Rogers et al. 2000), value networks (Allee 2002), and communities of practice (Lee 1999, Rogers et al. 2000, Wenger et al. 2002). A few of these key principles are illustrated below.

1. Unifying purpose. The Roanoke stakeholder organizations became a network when they arrived at a consensus about the value and goal of collaboration. Both FERC and USACE strongly encourage collaboration among the stakeholders in each of their processes. Once the stakeholders involved in the FERC negotiations lost their initial skepticism about the usefulness of the adaptive management paradigm and came to believe that adaptive management would serve the most interests most effectively, this consensus became a conviction to which the stakeholders were willing to bind themselves, by contract, for decades; the final settlement is in the form of a 40-yr contract among all the parties. Although few of the parties to the two negotiations agree completely on the best way to manage the Roanoke, all now agree that it is essential that they work together to manage the system adaptively so that it becomes more ecologically sustainable.

2. Independent yet interdependent members. Each member of the Roanoke network, whether an individual or a stakeholder organization, stands on its own while benefiting from being part the whole. The missions and agendas of the individual members cannot be compromised by their membership in the network (Pearsall 1984). No stakeholder in the Roanoke River negotiations has offered to compromise its mission, and much of the negotiation has focused on finding collaborative solutions that do not require such compromises. An emerging consensus among the parties holds that a well-crafted strategy for AEM is strengthened by the absence of such 
Fig. 3. Virtual network participants.

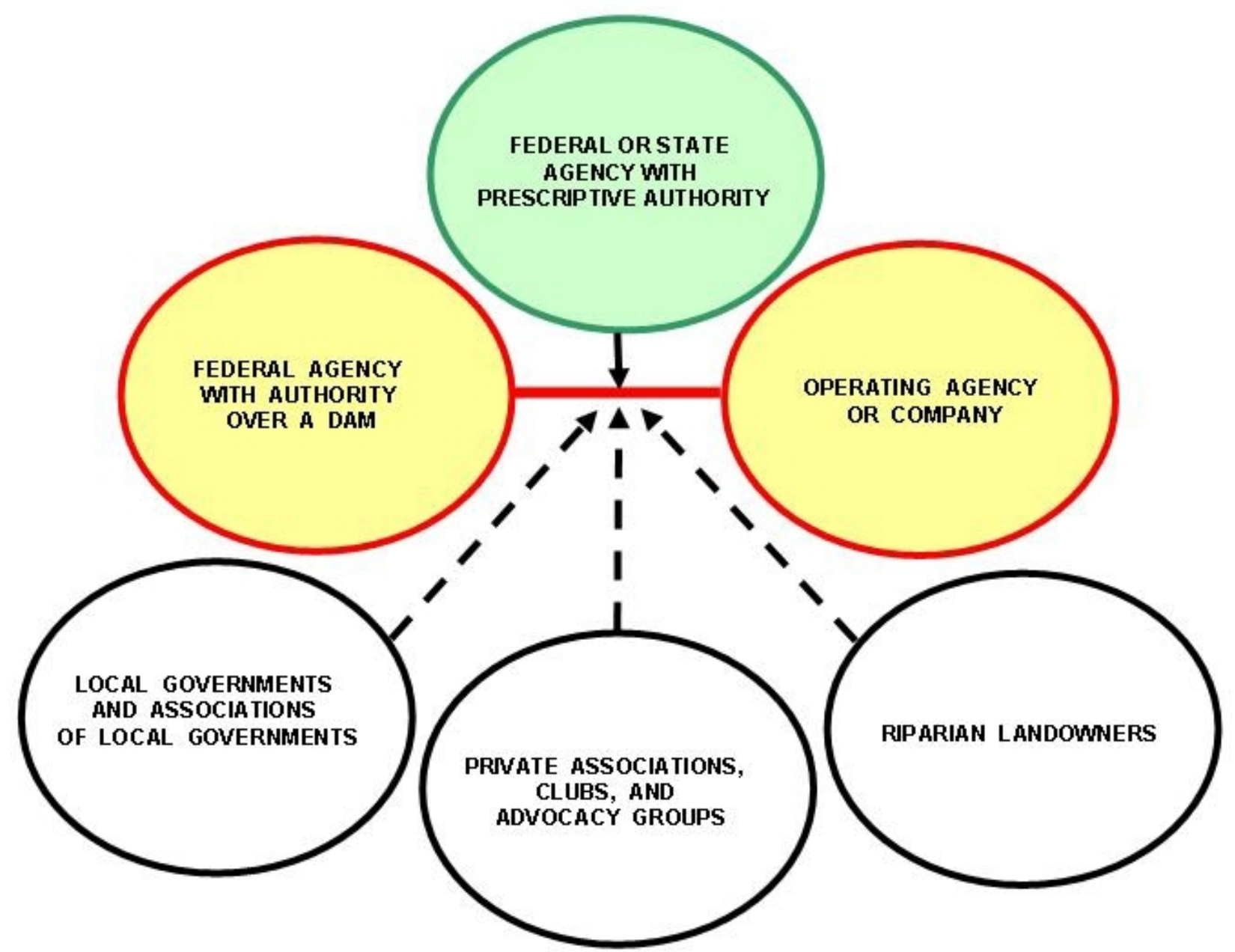

compromises, and that incremental, active adaptive management is the key strategy for avoiding such compromises. The parties intend and will be able to test alternative solutions against their own missions in real time.

3. Voluntary and informal links. The links that connect the Roanoke stakeholder organizations in various combinations are far more profuse and omnidirectional than in other types of organizations. These links continue to grow and develop as communication pathways increase and trust strengthens throughout the
Roanoke network. Characteristically, the links are redundant, resulting in network resilience and increased adaptive capacity (Berkes and Folke 1998, Berkes et al. 2003). Formal linkages tend to emerge and become institutionalized during formal negotiations and in agreement documents, but, in the Roanoke network, most of the linkages have developed informally among subsets of parties who are attempting to clarify issues, develop negotiating strategies, and crossanalyze the potential impacts of management strategies. 
Fig. 4. Federal Energy Regulatory Commission (FERC) and Dominion Power stakeholders.

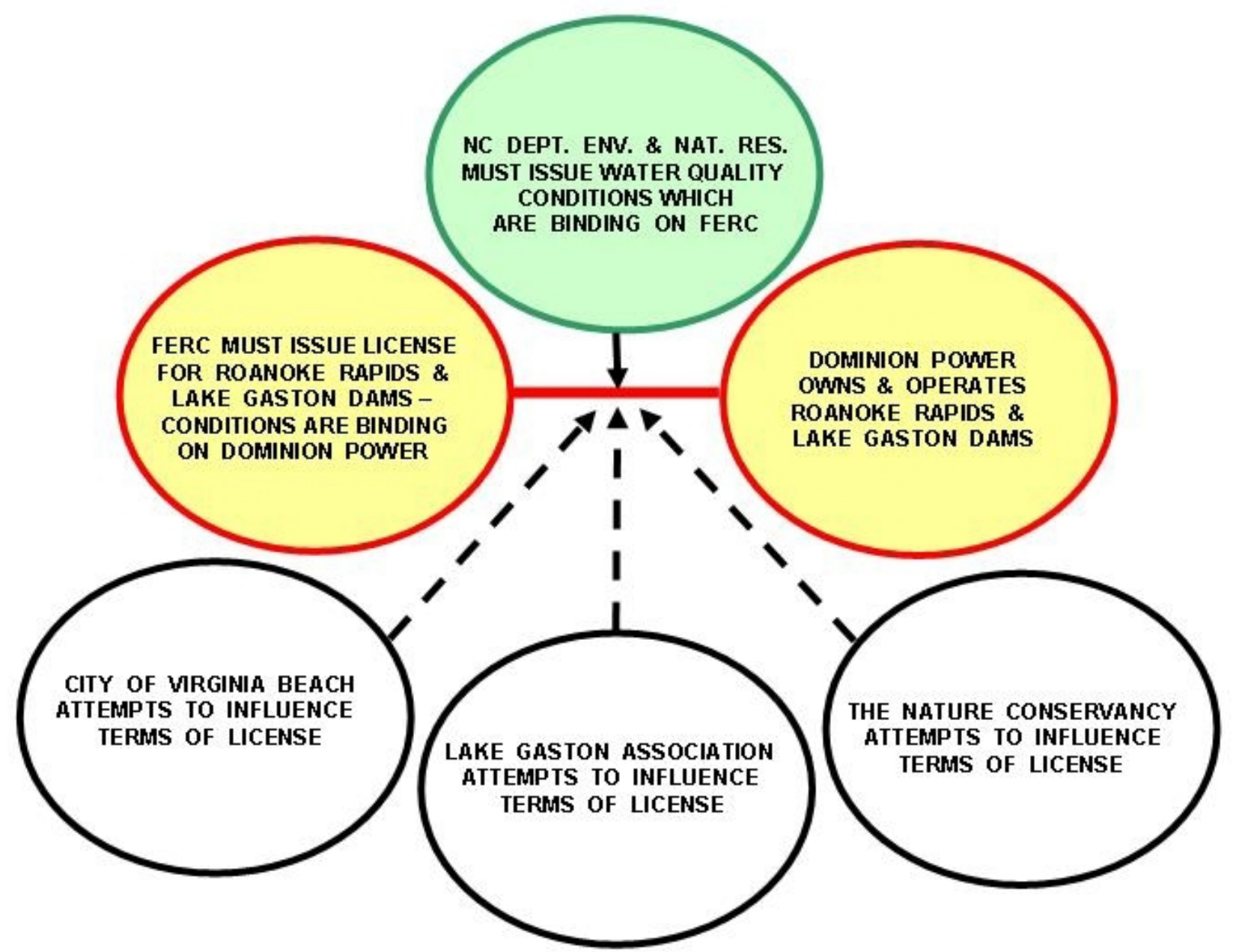

4. Multiple leaders. Networks generally are "leader-full," not leaderless. Each stakeholder in the network has something unique to contribute. Leadership tends to emerge from the intersection of agency commitment and agency expertise. For example, in the Roanoke negotiations, TNC has led the development of adaptive measures in general, while consulting with parties on issues outside TNC's mission on ways to constructively use adaptive strategies. Dominion has led the process of parsing and tracking issues. Virtually every stakeholder has led and continues to lead some significant component of the negotiating process. With more than one leader, the Roanoke network, as a whole, has greater resilience.

5. Multilevel, redundant, nonhierarchical integration. Virtual networks tend to be multilevel rather than flat; connections develop in response to needs and opportunities and last only as long as they serve essential purposes. The larger system, the virtual web itself, is the emergent, i.e., nondesigned, product, of this web of connections, integrated, not by authority or imposition, but by common purposes, e.g., AEM for a critical resource. The virtual web 
Fig. 5. The Nature Conservancy initiative.

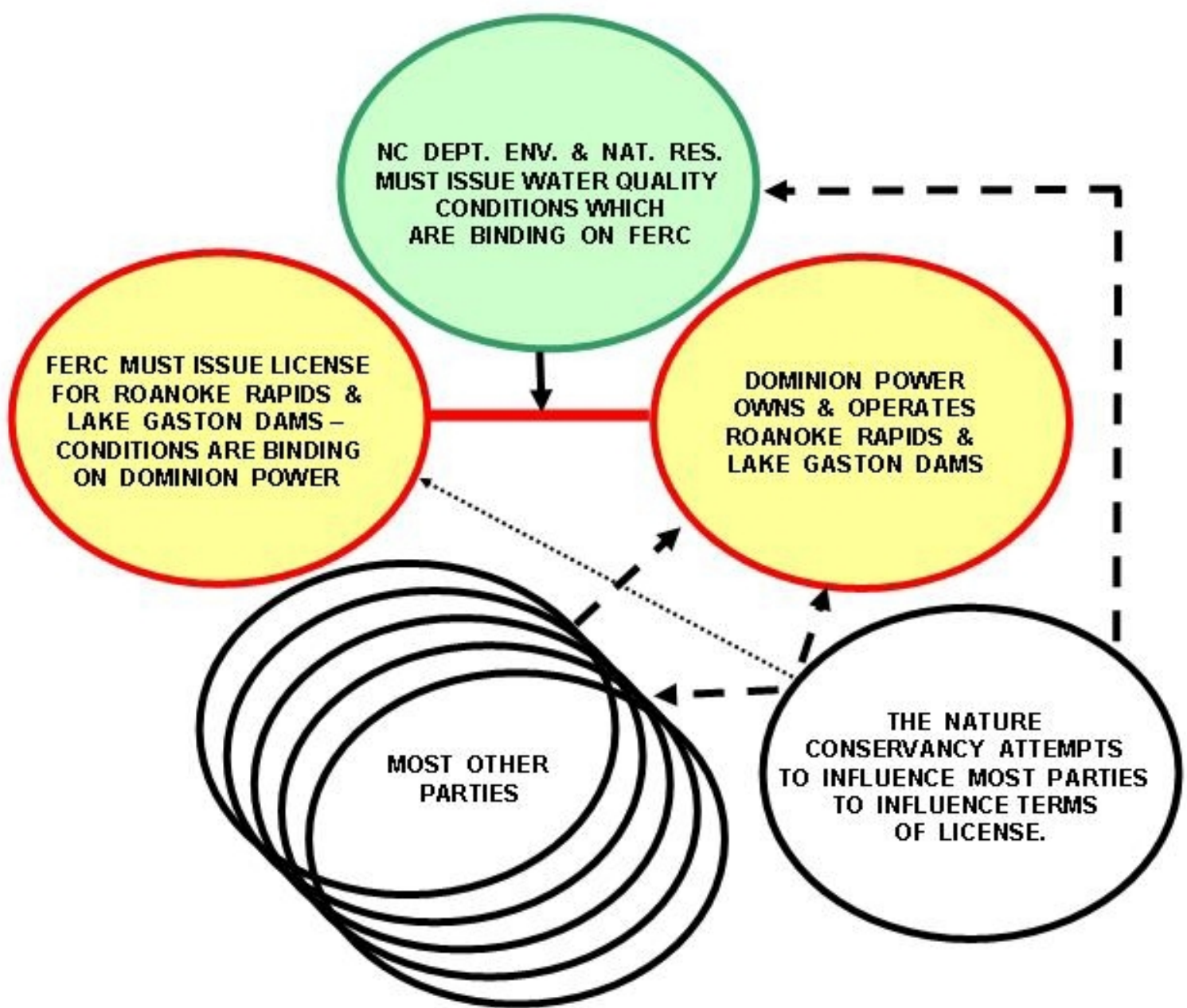

of Roanoke River stakeholders does not have a center or a top, but consists itself of many overlapping and redundant smaller webs that evolve from growing recognition of common goals, challenges, and opportunities. Some of these smaller component webs will last for decades, now formalized in the language of the settlement or the FERC license. Others last for relatively little time, emerging in response to a circumstance that can be directly resolved. When it became apparent on the Roanoke that monitoring in the postlicensing, post-216 study world was likely to be fragmented and incomplete, a group of terrestrial ecologists and agency representatives led by the USFWS developed a parsimonious table of monitoring needs that included a list of the species, groups of species, and natural community types to be monitored to detect and quantify the impacts of either or both of the USACE or Dominion operations. Once the table was generated, the group disbanded. Now, in the context of the USACE 216 study, it has reformed with slightly altered membership. The team for the adaptive management of the Roanoke River, like an ecosystem, is not a designed system, but it is well integrated thanks to the common 
Fig. 6. Connected stakeholders.

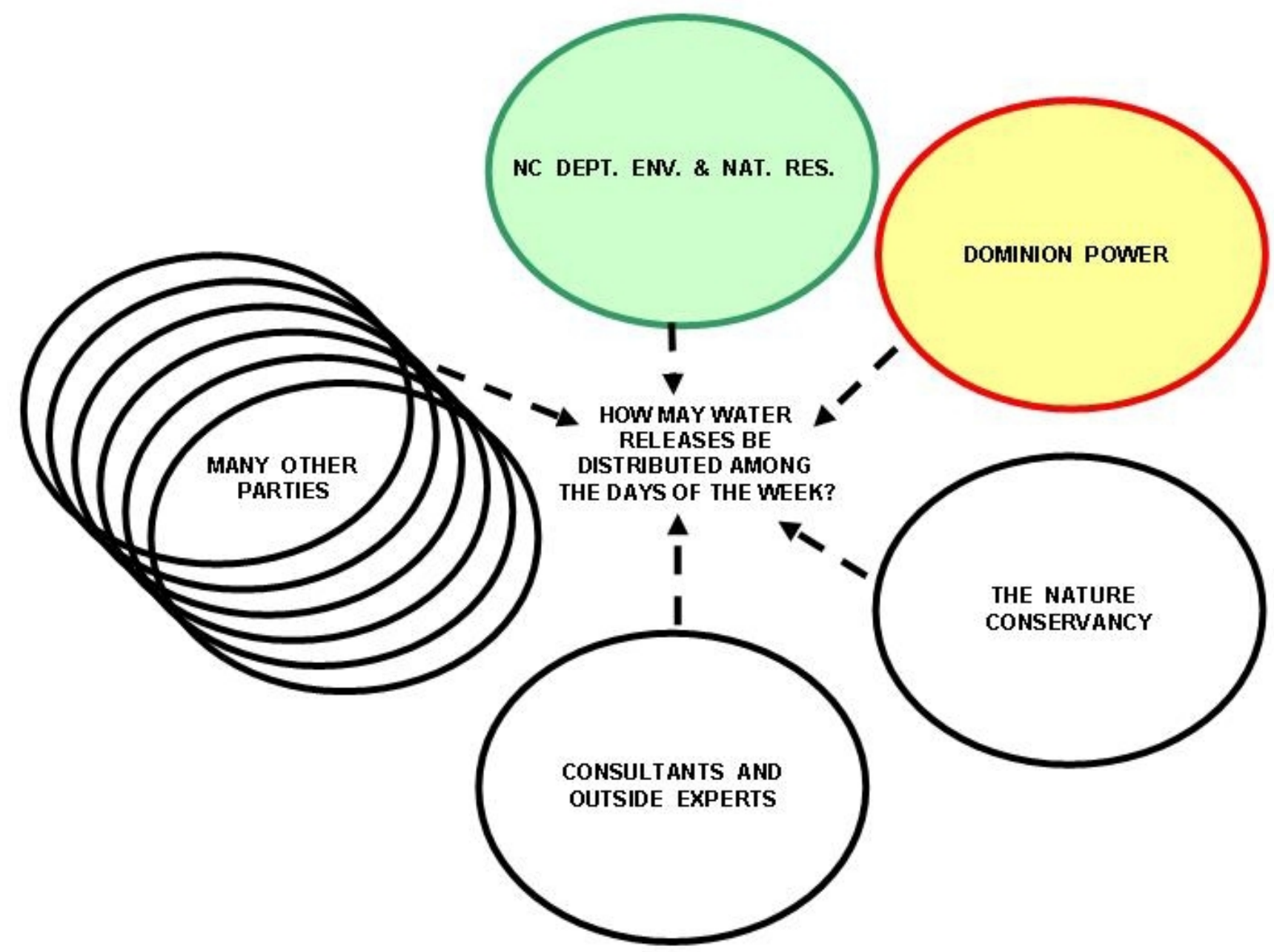

ground of a shared substrate and overlapping and co-dependent strategies.

6. Trustworthiness. This is also a key property of the Roanke network. The "spiral of trust" (Franke 1999) begins at the point at which members acknowledge the legitimacy of each other's goals. Commitment to the partnership offers both a forum of stability and a high level of motivation for all collaborating organizations. When this virtual network has become a conscious, intentional learning community, it creates its own web culture (Franke 1999). Initially, TNC declared that it recognized and was prepared to defend the legitimate interests of all the parties, and challenged all the parties to adopt the same position as a foundation for negotiations. Resistance to this proposal was very high, and it was never formally adopted, but as is evidenced by the settlement itself, this principle emerged over time as the unifying principle for the network. Without it, it would have been impossible to find an optimum solution that maximized total benefits and distributed costs fairly, i.e., the "Pareto optimum”, of Stokey and Zeckhauser (1978). 
In both sets of negotiations on the Roanoke, the mutual recognition of the legitimacy of stakeholder goals, based in large part on developing trust, was far more challenging than building a shared vision, but once trust was established, the vision was apparent. For example, many of the parties with mainly economic interests were deeply suspicious of TNC and other agencies with primarily environmental interests. Those stakeholders with mainly economic interests incorrectly suspected that the environmental stakeholders might want to have the dams removed. When it was finally clear that all parties considered the dams a benefit to the system and that the issues that required resolution were entirely about their operations rather than their existence, many obstacles to communication and negotiation simply disappeared.

The shared learning made possible through the virtual network created a conceptual infrastructure for addressing ecosystem management issues. The Roanke network also fostered informal relationships, e.g., humor and fellowship, among the various individual stakeholders. Within the network, stakeholders were able to discuss their various approaches to similar problems, offer ideas, ask for advice or examples of solutions tried elsewhere, and gain perspective on issues they faced in their own organizations. This process further served to enable stakeholders to move beyond the oversimplified yes-or-no thinking that tends to occur when decisions are being made on specific management proposals. When the individual stakeholders expanded their thinking to include the more complex interrelationships and impacts involved and the variety of options available to them, they were able to make better informed decisions based on progressively deeper learning about management of the ecosystem.

\section{The Roanoke River adaptive ecosystem management network as a learning organization}

Together the stakeholders in the Roanke network engaged in a continuous learning process as they created a virtual learning organization that did not exist conceptually until they joined to develop their collaboration processes. By its nature, an AEM network of stakeholder organizations provides the multiplicity of perspectives that require and then support thinking about thinking, and learning about learning. Anderson et al. (2003) refer to this sort of generative learning as "evolutionary problem solving." For instance, although the starting point for each stakeholder was the perspective and goals of his or her own organization, generative learning resulted in new ways of looking at resource issues and producing whole-system (systemic) solutions that transcended the boundaries and views of individual stakeholders. This was the product of network learning: the capacity to think together. Generative learning and consensus building through collaboration may be regarded as the core technologies of an AEM network (Anderson et al. 2003, Manring et al. 2003).

The disciplines that are necessary for the development of a learning organization (Senge $1990 a, b$, Senge et al. 1999) are also essential for an AEM network:

1. Creative pursuit of systemic solutions. The purpose of both a learning organization and an AEM network is to be creative in finding systemic solutions that satisfy the various stakeholder interests. The Pareto Optimum mentioned above is the set of potential solutions in which all of the benefits that could accrue to the stakeholders and all the benefits that potentially exist are distributed among the stakeholders (Stokey and Zeckhauser 1978). Ideally, the network will commit to finding the fairest distribution of net benefits among the Pareto Optimum set. This process depends, first, on mutual recognition of the legitimacy of individual stakeholder goals and, second, on the abilities of the people who comprise the network to build a shared vision that transcends their separate organizational boundaries and fosters genuine commitment. The essential outcome for long-term collaboration in an adaptive network is the set of actions the vision enables, not the vision itself (Fulmer and Keys 1998). The network must be able to build a conceptual infrastructure that supports systemic solutions.

2. Transcendent vision. The process of committing to the vision of the AEM network requires some degree of personal transformation on the parts of the individual members. Although the individuals join the network to represent the interests of their organizations, 
to be part of the generative process of creating systemic solutions these individuals must both share and grow their mental models and stretch to transcend their personal and organizational world views.

3. Community of commitment. Every stakeholder has a share in creating a community of commitment (Kofman and Senge 1993), which is the heart of the AEM network. Commitment to what? Ideally, the community of commitment is focused on the development of a culture of AEM, favoring evolutionary or experiment- and experiencebased generative learning about managing the ecosystem, rather than on one or more specific solutions. The nature of the commitment required to build a network for adaptive management goes beyond, but does not replace, the stakeholders $l^{\prime}$ commitments to their own organizations. It encompasses the individuall's commitment to the changes needed to manage the larger ecosystem and to seeing his or her organization as one, but only one, of the essential vehicles for bringing about such changes.

4. Holographic thinking. As the stakeholders collaborate to create an ecosystem perspective, they shift their thinking from the primacy of pieces, i.e., the world views of their individual organizations, to the primacy of the whole: from the absolute truths derived from the goals and assumptions of the individual stakeholder organizations, to coherent interpretations based on new collaborative, transformational ways of looking at the ecosystem. This new conceptual infrastructure, as developed by the AEM network, is analogous to holographic thinking (Senge 1990a). Senge explains:

"If you cut a photograph in half, each half shows only part of the whole image. But if you divide a hologram (a three-dimensional image created by interacting coherent light sources), each part, no matter how small, shows the whole image intact. Likewise, when a group comes to share a vision for an organization, each person sees an individual picture of the organization at its best. Each shares responsibility for the whole, not just for one piece. But the component pieces of the hologram are not identical. Each represents the whole image from a different point of view ... Furthermore, when you add up the pieces of a hologram, something interesting happens: The image becomes more intense, more lifelike. When more people come to share a vision, the vision becomes more real in the sense of a mental reality that people can truly imagine achieving. They now have partners, cocreators" (Senge 1990a).

A network for AEM seeks consensus around a systems view or holographic image such that each stakeholder's goals now also include the larger, holistic vision. AEM, the product of the network's collaboration and consensus-building processes, transcends the fragmentation of problem solving and the potentially competitive, reactive inclinations of the individual stakeholder organizations.

\section{The role of models}

Models that synoptically represent the whole system are perhaps the most effective tools for facilitating the emergence of systems perspectives, and thus holographic thinking. One essential characteristic of such models is that they produce products that can be visually appreciated and understood by nonexperts. Maps have proved to be powerful synoptic models; although they can be spatially comprehensive, individually they cannot be topically comprehensive. Individually, they represent single moments in time. Simulation models develop solutions including and then transcending the period for which data are available. Geographical Information Systems (GIS) create and manage electronic maps that can be overlaid. Combining simulation and GIS technologies is a powerful approach to developing synoptic perspectives for the total system. The resulting maps are both easy to understand and sophisticated in their content.

On the Roanoke, a model was developed that began with policies and prior conditions and yields flows, among other outputs (HydroLogics 1996). Flow outputs were presented as tables and, more often, as graphs of flow over time. These time series of flows were then translated by regression formulae and digital elevation data into GIS data sets to create maps of floods. The flood maps could then be overlaid on soils, property, vegetation, land-cover maps, and so on. Flood coverage overlaid on aerial photographs, i.e., digital orthophotos, turned out to 
be an especially useful combination. A set of policies could be proposed, and then the parties could watch as recognizable bits of the landscape disappeared under water, or did not. This is proving to be invaluable as a strategy for comprehending system-wide implications of complex policy sets. For example, until recently, both Dominion and the USACE operated on the belief that, as the volume of water released from the dams increased, so too did the amount of land inundated downstream. However, the models mentioned above were used to discover and then demonstrate that lower volumes of water released for longer periods would actually inundate more land downstream than higher volumes released quickly. With the resulting holographic perspective, lakeshore landowners, who wanted to release water quickly to hold lake levels constant, and downstream landowners, who wanted to be protected from floods, learned for the first time in the $50 \mathrm{yr}$ since the dams were built that their desires, which had always been assumed to be antagonistic, were actually resolved by the same systemic solution (Pearsall et al. 2005).

\section{Interorganizational transactions in the Roanoke River}

We now take a more focused look at the nature of the cross-scale interorganizational collaboration and power interactions presently emerging within the two Roanoke River processes. An AEM network such as the Roanoke network is shaped (1) by the collective activities of its stakeholders in collaborative arrangements mainly within the their common institutional fields, e.g., state and federal government, business, NGOs and stakeholder associations and clubs, and only rarely among different institutional fields, and (2) by the power of its stakeholders (Phillips et al. 2000, Berkes et al. 2003). For example, various government agencies regulating water quality push the AEM network to incorporate or develop close analogs for their existing water-quality rules, practices, and resources. Similarly, institutionalized rules, resources, and practices are more likely to be translated across institutional fields into the network collaboration when they originate in the fields of the collaboration's dominant members.

In 1995, after a period of sustained high flows in the Roanoke and associated high water in the floodplain forests, the USACE and Dominion abruptly reduced the flow to near the minimum legal release. Large quantities of hot, acidic, and deoxygenated water flowed into the channel, and the river experienced its largest recorded fish kill prior to 2003 (Fromm and Lebo 1997). Since then, a water quality "betterment plan" has been in place (USACE 1992). This plan requires that, following high flows during warm weather, the flows must be reduced gradually, in a series of discrete steps. This strategy causes the water to stay longer in the floodplain, where water quality continues to deteriorate, simultaneously harming riparian ecosystems and threatening the water quality in the river itself.

The year 2003 was the wettest year on record for the Roanoke, and water was forced into the floodplain and held there for several months. Landowners and managers urged the USACE to let the water out of the floodplain as quickly as possible to avoid forest mortality. Agencies accustomed to measuring success in terms of dissolved oxygen insisted that the betterment plan be followed to the letter and generally were unwilling to consider much flexibility in its implementation. The potential risk to trees, and for that matter, to fish, was a less tangible issue than parts per million of oxygen. Finally, it was determined that the water quality agency had the legal authority to enforce its view. Consequently, as one might predict (e.g., Holling 1995), conversations about flow management in this time of very high water became conversations exclusively about controlling dissolved oxygen. The adaptive management of the Roanke ecosystem was subsequently tabled in favor of the management of dissolved oxygen in the main channel and hence, the rules and practices of a single regulatory agency became the rules and practices of the whole group. In this case, institutional power, i.e., legal authority, combined with jealousy about the primacy of the regulatory mission to protect present levels of dissolved oxygen and prevent short-term impacts on fish, overrode the holistic ecosystem imperative to generate systemic solutions. Such systemic solutions, however, probably would have produced very long-term benefits for trees and fish, and arguably for water quality. Although water management during very wet years has become the subject of intense, ongoing negotiations among the stakeholders and the USACE, a resolution is not expected prior to the conclusion of the Section 216 study, currently projected for 2010 .

The production of new institutional rules and resources in a collaboration is more likely when the collaborating organizations face problems not 
previously addressed in the institutional fields of the collaboration's dominant members (Phillips et al. 2000). When no power dominates and no strategy is entrenched, then an AEM network moves quickly and relatively easily toward generative systems learning (e.g., Lee 1995). New mental models change problem definitions. As this happens, it creates the opportunity for the network to engage in learning about learning, or as Argyris and Schon (1978 and 1996) call it, "double-loop" or "selfquestioning learning." As the network interrogates and challenges its own assumptions through doubleloop learning, it gradually redefines its own world view and produces new rules for its own behavior in the context of an emergent epistemology. It adaptively manages the processes of sharing knowledge and learning in the form of "adaptive comanagement" (Berkes et al. 2003).

Although bank erosion is a significant issue on the Roanoke, none of the stakeholder agencies has developed institutional expertise on this subject. In fact, the stakeholders do not know what is causing this erosion. The erosion is the product of long-term bank inundation and/or rapid fluctuation of water levels. In other words, it could be attributable to Dominion's peaking strategies or to the USACE's flood-control strategies or both. An adaptive management plan was developed to establish baselines related to slope, position, and vegetation for selected vulnerable banks, experimentally manipulate flows, measure erosion, and learn from the results. Eventually, the parties hope to know which policies, implemented by which operator(s), are most responsible for bank erosion (Dominion Power et al. 2003). Formal hypotheses, measurement units, decision cycles and procedures, and measures of success are mandated by the settlement agreement. In the absence of a strong prior model in any of the stakeholder institutions, the new policies and procedures will necessarily originate and be congruent with the network's capacity for learning (Lee 1995).

\section{The diffusion of AEM network practices of the Roanoke River back to its stakeholder organizations}

It is important to consider the factors that affect the diffusion of rules and practices from network collaboration back to the institutional fields of the stakeholder organizations. After all, the lessons learned from the adaptive management of one ecosystem should be relevant to the formulation of new stakeholder networks and the adaptive management of other similar systems. This process of diffusion is not automatic, and it is not symmetrical. Organizations with relatively less power, e.g., regulatory authority and political power, will be more motivated to change the rules in their fields, whereas organizations with relatively more power, i.e., those in high-status positions, will tend to be more satisfied with and defensive of their own status quo (Bourdieu 1993). Although the stakeholders' power relative to that of the cocollaborators might ensure their ability to influence the networks processes, this collaborative power does not guarantee and could even inhibit the stakeholders' ability to influence their own institutional fields. Diffusion back to stakeholder organizations, and thence to the field, depends on the motivation and capability of the organizational actors, given their personal strategic positions (Phillips et al. 2000, Scheffer et al. 2002).

There is an alternative: through collaboration in an AEM network, high-status organizations may be influenced by low-status collaborators in ways that will impact the evolution of the field. For example, a low-status conservation group might be able to influence the development of national environmental policy through its collaborative efforts with major corporations and key government agencies (Douglas and Wildavsky 1982).

Ultimately, the capacity for motivated organizations to effect change in their own institutional contexts depends on the ability of their organizational actors to institutionalize the rules and practices they have helped to develop in the collaboration. There is a "constraining process" at work here, a "coercive isomorphism" that forces members of an institutional field to adopt similar structures and processes when facing similar environmental circumstances (DiMaggio and Powell 1983). "Coercive isomorphism occurs when organizations adopt [congruent] structures or practices in order to maintain a flow of resources, including legitimacy. These kinds of effects are often the explicit aim of collaborations around environment issues, where government, business, and environmentalists collaborate in the production of guidelines, regulations or policy" (Phillips et al. 2000).

We offer two cases in point from the Roanoke. In the first case, the negotiators elaborated on the institutionally sanctioned processes of the FERC 
negotiation to better fit the circumstances, and then, based on newly institutionalized expectations, exported those changes to the USACE negotiations and presumably beyond. In the second case, the relicensing negotiators changed the nature of the expected product from a weakly adaptive formula or prescription for ecosystem management to a permanent network supporting a strong and flexible adaptive process. Again, based on newly institutionalized expectations, this change probably will be incorporated into this and future USACE Section 216 products. We expect that both innovations will be propagated through FERC negotiations and Section 216 studies to adaptive management applications on other rivers.

\section{Case one}

Both the USACE Section 216 study and the FERC relicensing process are normally managed according to traditional models of draft-andpublish, review-and-comment, revise-and-publish, or call-and-response models of public participation, which unfortunately sometimes also include the fourth step of litigation. FERC has developed an alternative licensing process (ALP) for encouraging collaborative decision making (FERC Office of Hydropower Licensing 1996, Interagency Task Force on Improving Hydroelectric Licensing Processes 2000, Roos-Collins 2004). To Dominion's great credit, the company chose to follow this ALP. Although the USACE supports collaborative efforts, its formal process is still strongly based on the call-and-response paradigm. However, during the FERC negotiations, the negotiating team invented new, sometimes spontaneous, negotiating strategies and in the end adopted a general strategy of staying together after the license was issued to administer an AEM approach for the full period of the license. The FERC negotiations are several years older than the 216 negotiations, so both the negotiating and collaborating strategies of FERC are highly evolved, and quite distinct from those normally expected from FERC (even under the ALP), whereas the 216 negotiations are beginning to diverge from the call-and-response model that the USACE normally expects as the result of stakeholder activism developed during the FERC negotiations.

\section{Case two}

The terms of the settlement (Dominion Power et al. 2003) proposed by the parties for inclusion in the license provide the limits of Dominion's action goals for AEM and requirements for implementation, e.g., financial commitments to monitoring. In general, agencies with regulatory authority seldom proposed or initially supported adaptive strategies. Stakeholder organizations without regulatory authority and essentially without official mandate in the processes beyond the right of the public to provide input pressed hard for adaptive management agendas and, in the absence of tested and reliable intra-agency alternatives, the regulatory agencies accepted these proposals. In the process, the nonregulatory institutions created a more equal forum in which they had a newly invented status. Most of the stakeholders in the USACE process now expect to arrive at AEM solutions and standing commitments beyond the end of the 216 process. The USACE has now committed itself to this goal on the Roanoke.

It is too soon to know whether the agencies and institutions that are participating in the Roanoke River processes, and as a result are creating learning networks to practice AEM, will further attempt to internalize and extend the adaptive management paradigm. However, the complexity of ecosystems and the challenges of their management will probably enforce an isomorphism of adaptive strategies. In the end, it is probable that institutions without much power will have stimulated a network strategy that will eventually reshape its members, including those that came to the table with power and no thought of compromising it.

The phenomenon of coercive isomorphism leads to another set of useful propositions (Phillips et al. 2000) that can be illustrated through the Roanoke processes:

1. Rules, resources, and practices emerging out of a collaborative relationship become institutionalized in a stakeholder's field to the degree that the AEM network controls resources considered scarce and critical. For example, if the Roanoke network pays for and controls water quality data, it is more likely that the water-quality control agencies will adopt the adaptive methods of the network for water quality management and monitoring.

2. AEM practices that evolve in a collaborative relationship are likely to become institutionalized directly or by analogy in a stakeholder's field 
to the degree to which the network itself becomes an important forum for collective arrangements. The Roanoke FERC settlement proposes to track ecosystem responses by monitoring keystone species and communities (Dominion Power et al. 2003). If this approach succeeds as the standard operating procedure on the Roanoke, and five or six conservation agencies are engaged, as is intended, then this approach and these data are likely to be adopted by the USACE for its management of the Roanoke, and this approach is more likely to be improved upon and adopted by conservation agencies responding to hydrological alteration on other rivers.

3. Interorganizational collaboration most often occurs when the problems are complex and multifaceted, as is the case with environmental issues and AEM. Pritchard and Sanderson (2002) discuss the notion that innovation and collaboration are stimulated by disturbance (s) in the system at stake. The Roanoke River system and associated negotiations comprehensively illustrate this point.

4. Finally, stakeholders with strong histories of collaboration are more likely to have internal or institutional biases toward collaborative solutions as well as institutional structures and strategies supporting existing collaborations. The critical role of "pre-existing institutional structures in the development of collaboration, and consequently in the development of the solutions to these problems" should not be underestimated (Phillips et al. 2000).

\section{The nature of leadership, service, and transformation in the Roanoke network}

The learning organization paradigm offers a flexible approach to power and leadership in an AEM network. It is important to realize that a learning organization cannot be an externally imposed model. It is an internally generated vision of the type of organization that can thrive in a world of increasing interdependency and change (Kofman and Senge 1993). The creation of a learning organization in an AEM network depends on the willingness of its members to commit to building a shared vision of the ecosystem, disclosing and challenging mental models, and engaging in complex, evolutionary, systems-oriented thinking. Miles and Snow (1986) have suggested that this process happens best when a "net-broker" emerges to catalyze the establishment of a management network of diverse stakeholders committed to the values of generative learning and collaboration. Olsson et al. (2004) refer to the net-broker as the "policy entrepreneur" or the "key steward," thus capturing the net-broker's essential, dual nature as creator and steward of the emerging network.

The net-broker must initiate the negotiating process by identifying most, if not all, of the key players and determining when they should enter the network in relation to each other. A net-broker initiates development of the "interspecies connections" creating the blueprint for this new collaborative entity (Miles and Snow 1986). Initially, the netbroker stimulates the diverse stakeholders to identify their various motivations, goals, and attitudes. On the macro-organizational level, the net-broker manages the AEM network and may also serve as facilitator, coordinator, and moderator among the stakeholder members. The duties of the net-broker are illustrated with references to the two Roanoke negotiations, in which the norm has been for different brokers to emerge for each essential network function, i.e., the "leader-full" concept.

\section{Initiation and preparation of the network for AEM network}

A first task is to identify all the stakeholders with vested interests and complementary resources. In this preparation phase, the net-broker acts as a relationship promoter who contacts people, brings them together, and leads the dialogue and socializing process (Olsson et al. 2004). In both the FERC relicensing and the Section 216 study, initial net-brokering responsibilities were assumed by the owners of the dams, Dominion and the USACE. The main purpose of the net-broker is to create a common bond and to promote mutual trust for longterm effectiveness. Eventually, in both Roanoke processes, other parties besides the dam owners played key roles in this socialization. The net-broker can also become a "trust bridge." Stakeholders trust the net-broker and rely on the broker's recommendations about new and other stakeholders. When stakeholders don't know or trust each other, a first step toward mutual trust can be taken if they trust the net-broker's selections. In the Roanoke processes, no agency consistently served as a trust 
bridge, but the North Carolina Department of Environment and Natural Resources gradually assumed a pivotal role in the FERC process and transferred that leadership directly into the formative stages of the USACE process.

\section{Maintaining and improving the web collaboration}

The net-broker facilitates the processes that establish negotiations to define the problem, standardize practices, and speed up the partnering among the members of the AEM network. After a rocky beginning, Dominion filled this role admirably and consistently in the FERC process. In the USACE process, various USACE staff fill administrative coordination roles, and an executive committee composed of the District Chief and the two state co-sponsors provides policy leadership. However, the process facilitator function has not been assumed by any single party. As a result, the USACE process makes progress in the right direction, albeit very slowly.

\section{Promoting the partnership concept}

The managerial function of promoting the partnership concept is the role of the "caretaker" (Snow et al. 1992). Networks require continual enhancement if they are to operate smoothly and effectively. Thus, networks are always in a development process. When partnerships fail, the net-broker may also engage in disciplinary action. For example, if one stakeholder gains an advantage at the expense of other network members, the netbroker could serve to keep the playing field level. In the Roanoke processes, consistent with the concept of leader-full networks, the functions of caretaker have been filled by different parties at different times. However, in a process characterized by multiple leaders and consensus building, singular disciplinary actions are not an option. Both processes have sometimes, albeit rarely, suffered as a result. Without discipline, when a party becomes dissatisfied with the process, that party may withdraw, formally or informally, or withhold a consensus vote until the process is resolved. Resolution has sometimes been lengthy and expensive. This problem has largely, but not entirely, disappeared as socialization of the network has enhanced the power of consensus, and thus peer pressure.
Monitoring and continuously improving network performance

The net-broker tracks the internal and external environment of the network and identifies emerging needs so that it can adapt to changing conditions or circumstances. Sometimes the net-broker may propose an adaptation. The net-broker also keeps track of the resources and core competencies of the stakeholders as they bear on the network. The broker may search for new network members to provide missing or complementary resources. The netbroker shares several characteristics that are analogous to those of the entrepreneur who identifies and creates opportunities and combines resources to create new ventures. Like an entrepreneur (Franke 1999, Olsson et al. 2004), the most valuable asset of the net-broker in an AEM network is social capital, and the core competence is social contracting (Olsson et al. 2004). On the Roanoke, this net-broker duty has been distributed among the stakeholders, and the network itself consistently and aggressively fills this function.

Those stakeholders who fulfill the role of the netbroker or architect (Snow et al. 1992) of an AEM network need to take fully into account the power and pull of pre-existing institutional structures that might confound the efforts of the network to: (1) build a shared vision, (2) reveal and challenge stakeholder mental models, and (3) engage in systems thinking. When a network such as the one emerging on the Roanoke succeeds in achieving a collaborative approach to AEM, the collaborators carry skills, knowledge, and practices, i.e., the transfer of knowledge and process technology, from the network collaboration back to their stakeholder organizations. Thus, the solutions envisioned in one collaborative context could well have significant ramifications in another. The AEM network creates a new, virtual institution that is different from the institutions of the individual stakeholders. Through this new "superordinate" institution, the evolutionary processes of generative learning are continued and extended.

Learning organizations may be best led through stewardship, in the spirit of "servant leadership" (Greenleaf 1991). According to Greenleaf,

"A moral principle is emerging which holds that the only authority deserving one's allegiance is that which is freely and knowingly granted by the led to the leader in response to, and in proportion to, the clearly evident servant stature of the leader. Those 
who choose to follow this principle will not casually accept the authority of existing institutions. Rather, they will freely respond only to individuals who are chosen as leaders because they are proven and trusted as servants. To the extent that this principle prevails in the future, the only truly viable institutions will be those that are predominantly servant led" (Greenleaf 1977). The idea of servant leadership is particularly appealing for AEM networks because the sense of stewardship of their leaders operates on two levels: stewardship for the individuals who comprise the network and stewardship for the larger purpose or mission that underlies the enterprise, i.e., the responsible management of ecosystem resources. Leadership of this nature, i.e., committed to the vision of a learning organization and to the stewardship of its members, is best equipped to guide the AEM network toward the kind of learning that transforms its members.

Transformational learning is about evolving, about changing who we are (Kofman and Senge 1993). Organizations must eventually abandon their fixed and a priori notions about themselves and others. The stakeholders eventually realize that there are no problems or circumstances impinging on the ecosystem and its adaptive management network independent of how the members think and act in articulating and resolving those issues. Sometimes it appears as though both individuals and institutions would prefer to fail again and again rather than let go of some core belief or, for that matter, established habit. This explains the paradox of learning that is true at both the individual and organizational level: We claim we want to learn, but when we realize that we have to be open to being taught and risking failure, learning doesn't always look so good. For instance, during one of the USACE Section 216 negotiations, a Corps representative declared, "if we follow the manual, and forests die, it's an act of God, but if we deviate from the manual, anything that happens is the fault of the Corps." A culture must emerge, within the USACE and within the 216 negotiations, in which such a statement would be correctly recognized as absurd.

\section{CONCLUSION}

As in the example given above, standard operating procedures are the devil that is known, whereas venturing into new strategies for implementing adaptive ecosystem management (AEM) is, by definition, fraught with both uncertainty and risk.
Overall, AEM is about two kinds of systems: the natural ecosystems we aspire to manage and the social-cultural-political systems or virtual networks through which we attempt to implement our management. Both require adaptive approaches: the former because ecosystems are too complex for us to understand, the latter because every attribute of an effective AEM network co-evolves with every other in a human environment that changes rapidly and unpredictably (Gunderson et al. 1995, Holling 1995).

The model that we have presented illustrates the characteristics of a highly evolved AEM network as it gradually emerged from the last $12 \mathrm{yr}$ of interagency negotiations for the lower Roanoke River in North Carolina. We have explained the roles and relationships among the Roanoke stakeholders through an overlay of two paradigms: an emerging interorganizational network and the maturation of that network as a learning organization. Although stakeholder negotiations were conducted without explicit reference to the model, when we applied the model diagnostically, we found that there was a natural congruence between the organic evolution of the case study and the model. The Roanoke negotiations have corroborated the model and deepened our insights into the challenges and possibilities of intentionally fostering an AEM network. The model now serves as a compass to guide ongoing negotiations, through the role of The Nature Conservancy.

This vision of an AEM network of the Roanoke led through the spirit of stewardship to achieve generative, and thus transformational learning and consensual decision making, has been and continues to be daunting to realize. The stakeholders are challenged by the very nature of the network that they are trying to build, comprising loosely coupled political entities that sometimes have competing agendas and that invariably come to the table with large disparities in power, established practices, and levels of commitment. However, the result is worth the effort. When an AEM network such as the one evolving on the Roanoke consciously commits to becoming a learning organization, its members provide support, insights, and fellowship for each other to face the dangers of learning meaningful lessons. The network increases its own likelihood of success, defined here as a transformational, holistic, systemic, and adaptive approach to management of itself and the ecosystem(s) to which it is committed. 
Responses to this article can be read online at:

http://www.ecologyandsociety.org/vollo/iss2/art16/responses/

\section{Acknowledgments:}

The authors greatly appreciate early reviews and suggestions from Lance Gunderson, Ray Hilborn, Ida Lynch, Lynn Maguire, Dirk Roux, and two anonymous reviewers, and editorial assistance from Carrie Banks.

\section{LITERATURE CITED}

Allee, V. 2002. The future of knowledge: increasing prosperity through value networks. ButterworthHeinemann, Boston, Massachusetts, USA.

Anderson, J. L., R. W. Hilborn, R. T. Lackey, and D. Ludwig. 2003. Watershed restoration-adaptive decision making in the face of uncertainty. Pages 203-232 in R. C. Wissmar and P. A. Bisson, editors. Strategies for restoring river ecosystems: sources of variability and uncertainty in natural and managed systems. American Fisheries Society, Bethesda, Maryland, USA.

Argyris, C., and D. Schon. 1978. Organizational learning: a theory-in-action perspective. AddisonWesley, Reading, Massachusetts, USA.

Argyris, C., and D. Schon. 1996. Organizational learning II: theory, method and practice. Addison Wesley, Reading, Massachusetts, USA.

Berkes, F., and C. Folke. 1998. Linking social and ecological systems: management practices and social mechanisms for building resilience. Cambridge University Press, Cambridge, UK.

Berkes, F., J. Colding, and C. Folke. 2003. Navigating social-ecological systems: building resilience for complexity and change. Cambridge University Press, Cambridge, UK.

Bourdieu, P. 1993. Sociology in question. Sage Publications, London, UK.

Bovasso, G. 1992. A structural analysis of the formation of a network organization. Group and Organization Management 17:86-106.

Christensen, N. L., A. M. Bartuska, J. H. Brown, S. Carpenter, C. D'Antonio, R. Francis, J. F. Franklin, J. A. MacMahon, R. F. Noss, D. J. Parsons, C. H. Peterson, M. G. Turner, and R. G. Woodmansee. 1996. The report of the Ecological Society of America Committee on the scientific basis for ecosystem management. Ecological Applications 6:665-691.

Dewitt, J. 1994. Civic environmentalism. Issues in Science and Technology 10(4):30-35.

DiMaggio, P. J., and W. W. Powell. 1983. The iron cage revisited: institutional isomorphism and collective rationality in organizational fields. American Sociological Review 48:147-160.

Dominion Power. 2003. Virginia Electric and Power Company d/b/a Dominion Virginia Power / North Carolina Power, Roanoke Rapids and Gaston Hydroelectric Project, FERC Project No. 2009 Offer of Settlement. Law Offices of Grammer Kissel Robbins Skancke Edwards, Washington, D.C., USA.

Douglas, M., and A. Wildavsky. 1982. Risk and culture. University of California, Berkeley, California, USA.

Easterby-Smith, M. M., and L. Araujo. 1999. Current debates and opportunities. Pages 5-7 in M. Easterby-Smith, J. Burgoyne, and L. Araujo, editors. Organizational learning and the learning organization. Sage, London, UK.

Easterby-Smith, M. M., J. Burgoyne, and L. Araujo, editors. 1999. Organizational learning and the learning organization. Sage, London, UK.

Easterby-Smith, M. M., M. Crossan, and D. Nicolini. 2000. Organizational learning: debates past, present and future. Journal of Management Studies 37:783-796.

Easterby-Smith, M. M., and M. Lyles. 2003. Blackwell handbook of organizational learning and knowledge management. Blackwell, Oxford, UK.

Easterby-Smith, M. M., R. Snell, and S. Gherardi, editors. 1998. Organizational learning and the learning organization: diverging communities 
of practice? Management Learning (Special Issue) 29(3):259-272.

Federal Energy Regulatory Commission (FERC), Office of Hydropower Liscencing. 1996. Guidelines for the Applicant Prepared Environmental Assessment (APEA) Process. Washington, D.C., USA.

Feyerherm, A. E. 1995. Changing and converging mind-sets of participants during collaborative environmental rule-making: two negotiated regulation case studies. Research in Corporate Social Performance and Policy (Supplement) 1:231-257.

Franke, U. J. 1999. The virtual Web as a new entrepreneurial approach to network organizations. Entrepreneurship and Regional Development 11:203-230.

Fromm, J., and M. E. Lebo. 1997. Evaluation of Roanoke River betterment plan to maintain adequate DO levels. Weyerhaeuser Southern Environmental Field Station. New Bern, North Carolina, USA.

Fulmer, R. M., and J. B. Keys. 1998. A conversation with Peter Senge: new developments in organizational learning. Organizational Dynamics 27:33-41.

Greenleaf, R. K. 1977. Servant leadership: a journey into the nature of legitimate power and greatness. Paulist Press, New York, New York, USA.

Greenleaf, R. K. 1991. The servant as leader. Robert K. Greenleaf Center, Indianapolis, Indiana, USA.

Gulati, R., and M. Gargiulo. 1999. Where do interorganizational networks come from? American Journal of Sociology 104:1439-1493.

Gunderson, L. H., C. S. Holling, and S. S. Light. 1995. Barriers broken and bridges built: a synthesis. Pages 489-532 in L. H. Gunderson, C. S. Holling, and S. S. Light, editors. Barriers and bridges to the renewal of ecosystems and institutions. Columbia University Press, New York, New York, USA.

Holling, C. S. 1978. Overview and conclusions: the approach. Pages 1-142 in C. S. Holling, editor.
Adaptive environmental assessment and management. Wiley Interscience, Chichester, UK.

Holling, C. S. 1982. Science for public policy: highlights of adaptive environmental assessment and management. Pages 78-91 in W. T. Mason, Jr., and S. Iker, editors. Research on fish and wildlife habitat. U.S. Environmental Protection Agency, Washington, D.C., USA.

Holling, C. S. 1995. What barriers? What bridges? Pages 3-34 in L. H. Gunderson, C. S. Holling, and S. S. Light, editors. Barriers and bridges to the renewal of ecosystems and institutions. Columbia University Press, New York, New York, USA.

Holling, C. S., and G. K. Meffe. 1996. Command and control and the pathology of natural resource management. Conservation Biology 10:328-337.

Howes, J., and J. Dewitt. 1998. Resolving the paradox of environmental protection. Issues in Science and Technology 14(4):57-65.

HydroLogics. 1996. Roanoke River Basin Reservoir operations model. Raleigh, North Carolina, USA.

Imperial, M. T. 1999. Institutional analysis and ecosystem management: the institutional analysis and development framework. Environmental Management 24:449-465.

Interagency Task Force on Improving Hydroelectric Licensing Processes. 2000. Guidelines for participating in the alternative licensing process. American Rivers, Washington, D.C., USA.

Kofman, F., and P. M. Senge. 1993. Communities of commitment: the heart of learning organizations. Organizational Dynamics 22:4-24.

Lave, J., and E. Wenger. 1991. Situated learning: legitimate peripheral participation. Cambridge University Press, Cambridge, UK.

Lee, K. N. 1995. Deliberately seeking sustainability in the Columbia River basin. Pages 214-238 in L. H. Gunderson, C. S. Holling, and S. S. Light, editors. Barriers and bridges to the renewal of ecosystems and institutions. Columbia University Press, New York, New York, USA.

Lee, K. N. 1999. Appraising adaptive management. 
Conservation Ecology 3(2):3. [online] URL: www.consecol.org/vol3/iss2/art3.

Lipnack, J. H., and J.Stamps. 1997. Virtual teams, reaching across space, time, and organizations with technology. John Wiley, New York, New York, USA.

Manring, S. L. G., W. Rivkin, and M. D. Rivkin. 2003. The application of network and learning organization models to improve ecosystem management: Monroe 2020 case study. Environmental Practice 5(2):13-27.

Miles, R. E., and C. C. Snow. 1986. Network organizations: new concepts for new forms. California Management Review 28:62-73.

Olsson, P., C. Folke, and T. Hahn. 2004. Socialecological transformation for ecosystem management: the development of adaptive co-management of a wetland landscape in southern Sweden. Ecology and Society 9(4):2. [online] URL:

www.ecologyandsociety.org/vol9/iss4/art2.

Pearsall, S. 1984. Multi-agency planning for natural areas in Tennessee. Public Administration Review 44:43-48.

Pearsall, S., B. J. McCrodden, and P. A Townsend. 2005. Adaptive management of flows in the lower Roanoke River, North Carolina, USA. Environmental Management 35(4):353-367.

Erratum

Phillips, N., T. B. Lawrence, and C. Hardy. 2000. Inter-organizational collaboration and the dynamics of institutional fields. Journal of Management Studies 37:23-43.

Podolny, J. M., and K. L. Page. 1998. Network forms of organization. Annual Review of Sociology 24:57-76.

Powell, W. W. 1990. Neither market nor hierarchy: network forms of organization. Research in Organizational Behavior 12:295-336.

Prato, T. 2003. Adaptive management of large rivers with special reference to the Missouri River. Journal of the American Water Resources Association 39:935-946.

Pritchard, L., Jr., and S. E. Sanderson. 2002. The dynamics of political discourse in seeking sustainability. Pages 147-169 in L. H. Gunderson and C. S. Holling, editors. Panarchy: understanding transformations in human and natural systems. Island Press, Washington, D.C., USA.

Richter, B. D., R. Mathews, D. L. Harison, and R. Wigington. 2003. Ecologically sustainable water management: managing river flows for ecological integrity. Ecological Applications 13:206-224.

Rogers, K., D. Roux, and H. Biggs. 2000. Challenges for catchment management agencies: lessons from bureaucracies, business, and resource management. Water SA 26:505-511.

Roos-Collins, R. 2004. Integrated licensing process: new hope for efficient regulation of nonfederal hydropower projects. Trends-ABA Section of Environment, Energy, and Resources Newsletter 35:8-9.

Scheffer, M., F. Westley, W. A. Brock, and M. Holmgren. 2002. Dynamic interactions of societies and ecosystems-linking theories from ecology, economy, and sociology. Pages 195-239 in L. H. Gunderson and C. S. Holling, editors. Panarchy: understanding transformations in human and natural systems. Island Press, Washington, D.C., USA.

Schneider, M., J. Scholz, M. Lubell, D. Mindruta, and M. Edwardsen. 2003. Building consensual institutions: networks and the national estuary program. American Journal of Political Science 47:143-156.

Selin, S., and D. Chavez. 1995. Developing a collaborative model of environmental planning and management. Environmental Management 19:189-195.

Senge, P. M. 1990a. The fifth discipline: the art and practice of the learning organization. Doubleday/ Currency, New York, New York, USA.

Senge, P. M. 1990b. The leader's new work: building learning organizations. Sloan Management Review Reprint Series 32:7-23.

Senge, P. M., A. Kleiner, C. Roberts, R. Ross, G. Roth, and B. Smith. 1999. The dance of change: the challenges of sustaining momentum in learning organizations. Doubleday/Currency, New York, 
New York, USA.

Skyrme, D. J. 1999. Knowledge networking: building the collaborative enterprise. Boston, Massachusetts, USA.

Snow, C. S., R. E. Miles, and H. J. Coleman. 1992. Managing 21st century network organizations. Organizational Dynamics 20:5-16.

Stokey, E., and R. Zeckhauser. 1978. A primer for policy analysis. Norton, New York, New York, USA.

U.S. Army Corps of Engineers (USACE). 1992. Water control plan for John H. Kerr Dam and Reservoir. Wilmington, North Carolina, USA.

U.S. Army Corps of Engineers (USACE). 2001. Reconnaissance report: John H. Kerr Dam and Reservoir, Virginia and North Carolina (Section 216): lower Roanoke River. Wilmington, North Carolina, USA.

Van Alstyne, M. 1997. The state of network organization: a survey in three frameworks. Journal of Organizational Computing and Electronic Commerce 7:83-151.

Walters, C. J. 1997. Challenges in adaptive management of riparian and coastal ecosystems. Conservation Ecology 1(2):1. [online] URL:

www.consecol.org/vol1/iss2/art1.

Walters, C.J., and C.S.Holling. 1990. Large-scale management experiments and learning by doing. Ecology 71:2060-2068.

Wenger, E., R. McDermott, and W. M. Snyder. 2002. Cultivating communities of practice. Harvard Business School Press, Cambridge, Massachusetts, USA.

Westley, F. 1995. Governing design: the management of social systems and ecosystems management. Pages 391- 427 in L. H. Gunderson, C. S. Holling, and S. S. Light, editors. Barriers and bridges to the renewal of ecosystems and institutions. Columbia University Press, New York, New York, USA.

Westley, F. 2002. The devil in the dynamics: adaptive management on the front lines. Pages 333-360 in L. H. Gunderson and C. S. Holling, editors. Panarchy: understanding transformations in human and natural systems. Island Press, Washington, D.C., USA.

Westley, F., S. R. Carpenter, W. A. Brock, C. S. Holling, and L. H. Gunderson. 2002. Why systems of people and nature are not just social and ecological systems. Pages 103-119 in L. H. Gunderson and C. S. Holling, editors. Panarchy: understanding transformations in human and natural systems. Island Press, Washington, D.C., USA

Wondolleck, J., and S. L. Yaffee. 2000. Making collaboration work: lessons from innovation in natural resource management. Island Press, Washington, D.C., USA. 